\title{
A CONFIRMATORY HOLDING TIME STUDY FOR PURGEABLE VOCS IN WATER SAMPLES
}

O. R. West, C. K. Bayne, R. L. Siegrist, W. H. Holden, Oak Ridge National Laboratory, Oak Ridge, TN, 37831; D. W. Bottrell, Department of Energy, Washington, DC, 20874

\section{$\underline{\text { Abstract }}$}

Analyte stability during pre-analytical storage is essential to the accurate quantificalicn of contaminants in environmental samples. This is particularly true for volatile organic compounds (VOCs) which can easily volatilize and/or degrade during sample storage. Recognizing this, regulatory agencies require water samples be collected in vials without headspace and stored at $4^{\circ} \mathrm{C}$, and that analyses be conducted within 14 days, even if samples are acid-preserved. Since the selection of a 14-day holding time was largely arbitrary, the appropriateness of this requirement must be re-evaluated. The goal of the study described here was to provide regulatory agencies with the necessary data to extend the maximum holding time for properly preserved VOC water samples to 28 days. An extensive stability experiment was performed on freshly-collected surface water spiked with a suite of 44 purgeable VOCs. The samples were contained in $40-\mathrm{mL}$ glass vials with no headspace, preserved with $250 \mathrm{mg}$ of $\mathrm{NaHSO}_{4}$ and stored at $4^{\circ} \mathrm{C}$. For a majority of the 44 VOCs included in this study, concentration changes were $<10 \%$ of the initial values after 28 days of storage. Maximum holding times calculated from the stability data using the "practical reporting time" approach [Bayne et al., 1994] were predominantly greater than 28 days. This study showed that a 28 -day holding time for properly preserved VOC water samples would not jeopardize the measurement of target VOCs. This holding time extension would benefit the regulated community, particularly government agencies with large-scale compliance sampling programs such as the Department of Defense and Department of Energy. The suggested modification of holding times can also improve the efficiency of commercial laboratories through simplified sample management. Application of this study's results to data review would also improve the analytical data validation process by providing an alternative to the currently "one-size-fits-all" accept or reject approach that is very costly but not technically defensible.

Introduction

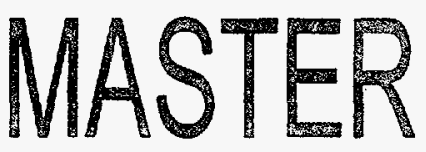

Analyte stability during pre-analytical storage is essential to the accurate quantification of contaminant levels in environmental samples. This is particularly true for volatile organic compound (VOC) analysis, since some of these target analytes can volatilize and/or degrade during sample storage. To reduce the impact of these transformation mechanisms on VOC analyses, regulatory agencies require that water samples be collected without headspace in $40-\mathrm{mL}$ vials with Teflon-lined septum caps, acidified to $\mathrm{pH} \sim$, and stored at $4^{\circ} \mathrm{C}$. Furthermore, analytical data are considered valid only if the analyses are conducted within 14 days of sample collection ( 7 days if samples are not acidified). This maximum

\section{DISTAIBUTION OF THIS DOCUMENT IS}

*Oak Ridge National Laboratory is managed by Lockheed Martin Research Corp. for the U.S. Department of Energy under contact DE-AC05-96OR22464. 


\section{DISCLAIMER}

Portions of this document may be illegible in electronic image products. Images are produced from the best available original document. 


\section{DISCLAIMER}

This report was prepared as an account of work sponsored by an agency of the United States Government. Neither the United States Government nor any agency thereof, nor any of their employees, makes any warranty, express or implied, or assumes any legal liability or responsibility for the accuracy, completeness, or usefulness of any information, apparatus, product, or process disclosed, or represents that its use would not infringe privately owned rights. Reference herein to any specific commercial product, process, or service by trade name, trademark, manufacturer, or otherwise does not necessarily constitute or imply its endorsement, recommendation, or favoring by the United States Government or any agency thereof. The views and opinions of authors expressed herein do not necessarily state or reflect those of the United States Government or any agency thereof. 
holding time was arbitrarily set and specified in 40CFR Part 136 [1979], and has since been adopted by other regulatory programs and for application to other environmental media [40CFR Part 136, 1984; EPA, 1986]. The appropriateness of this requirement must be re-evaluated since compliance with this 14-day holding time can and has been difficult and costly for sample collectors, data users and analytical laboratories. Recent Superfund Guidance [EPA, 1994] attempts to address the problem by relying on data validators' judgment to assess the impact of missed holding times on analytical measurements. However, this has still led to unequivocal rejection of data when prescribed holding times are missed, and more specific guidance backed by scientific data is needed from regulatory agencies [Bottrell, 1995].

Previous stability studies [Maskarinec et al., 1989; Bottrell et al., 1989] have demonstrated that a majority of purgeable volatile organic compounds in properly preserved VOC water samples (acidified, no headspace, $4^{\circ} \mathrm{C}$ storage) are stable for time periods well over 14 days. The goal of this study is to confirm these previous studies, as well as to provide regulatory agencies with the necessary data to extend the maximum holding time for properly preserved VOC water samples to 28 days.

\section{Experimental Methods}

The stability study was performed on surface water collected from a tributary of the Clinch River in Oak Ridge, TN. Water samples were prepared following the procedure described by Maskarinec et al. [1989]. A clean 3-L Tedlar bag was filled with two liters of surface water. Measured aliquots of VOC standard solutions were injected into the water-filled Tedlar bag through the bag's septum port. The water-filled Tedlar bag was shaken for 1-min, and allowed to equilibrate at room temperature for $20 \mathrm{~min}$. After equilibration, the spiked water was distributed into an appropriate number of pre-cleaned $40-\mathrm{mL}$ VOA vials with Teflon-lined ( 0.010 -in thick) silicone septum caps. Two hundredfifty milligrams of $\mathrm{NaHSO}_{4}$ were placed in each vial prior to filling. Each vial was completely filled (i.e., with no headspace) and stored at $4^{\circ} \mathrm{C}$ prior to analysis. Two sets of samples were prepared, one set was spiked to 20-ppb (W1) while a second set was spiked to 200-ppb (W2). At 1, 8, 15,22, 29, 35, and 71 days after sample preparation, four samples from each set were analyzed for VOCs. Analyses followed the purge-andtrap (PT) method in SW846-8260A [EPA, 1986], except that all calibrations were performed in reagent water that had been acidified to $\mathrm{pH} \sim 2$ with reagent-grade $\mathrm{NaHSO}_{4}$ (resulting $\mathrm{pH}$ was 2.4-2.6). Further experimental details are given in a forthcoming report and publications [West et al., 1996].

\section{Results}

Regression lines were fitted to the data for concentration vs analysis day (see Table 1 for a select number of compounds). Measurement variability [i.e., relative measurement error (\%RME)] for each compound within each sample set was estimated as follows: 


$$
\% R M E=\frac{S_{o} \times 100 \%}{C_{o}},
$$

where $S_{o}$ is the square root of the mean-square error for the linear regression residuals, and $C_{o}$ is the extrapolated concentration on Day 0 . Calculated values for \%RME were predominantly less than $15 \%$ in both sets $\mathrm{W} 1$ and $\mathrm{W} 2$, with values being lower in set $\mathrm{W} 1$ (20 ppb spike). These low values indicate that scatter in the data was generally minimal, and that concentration trends with time were less likely masked by measurement variability. Such masking of concentration trends may have occurred with vinyl chloride, which exhibited the highest \%RME in both sample sets $(43 \%$ and $33 \%)$. Statistically insignificant changes in vinyl chloride concentration with time may have been due to large measurement variability. However, a statistically significant negative slope was observed in vimyl acetate in both sets $\mathrm{W} 1$ and $\mathrm{W} 2$, despite a relatively large \%RME ( $21 \%$ and $29 \%$ ). For this compound, the concentration change with time was large enough to offset the masking effects of data scatter.

Changes in concentration after 28 days of storage (last column in Table 1) were predominantly low relative to the initial concentrations. Out of 44 analytes, concentration changes exceeded $10 \%$ for only three compounds in set W1 [vinyl acetate (42\%), cis-1,3-dichloropropene (11\%), and trans-1,4-dichloro-2-butene $(20 \%)$ ]. Concentration changes exceeded $10 \%$ for a larger number of compounds in set $\mathrm{W} 2$, including trichlorofluoromethane (15\%), acrolein (25\%), carbon disulfide (17\%), vinyl acetate $(42 \%)$, cis-1,3-dichloropropene $(14 \%)$, trans-1,3-dichloropropene $(12 \%)$, tetrachloroethene $(16 \%)$, and trans-1,2-dichloro-2-butene (26\%). For compounds exhibiting non-significant slopes (Table 2), maximum holding times (MHTs) were set to 71 days, i.e., the duration of the stability experiment. For compounds with significantly negative slopes, $M H T$ s were calculated from the stability data using "practical report time" analysis [Bayne et al. 1994]. Results of the analysis are presented in Table 2; details of the analysis are given in [West et al. 1996]. The compounds were subdivided into 3 groups (see Table 2): (1) VOCs which have MHTs greater than 28 days (Group 1), (2) VOCs which have $M H T$ s less than 28 days but for which the relative change in concentration on the 28 th day was $<10 \%$ of the initial value, and (3) VOCs which have $M H T$ s less than 28 days and the relative change in concentration on the 28th day was $>10 \%$. 
Table 1. Summary of linear regression on stability data for select compounds.

\begin{tabular}{|c|c|c|c|c|c|c|c|}
\hline & \multirow{2}{*}{$\begin{array}{l}\text { No. of } \\
\text { data } \\
\text { points }\end{array}$} & \multicolumn{2}{|c|}{ Regression gammeters } & \multirow{2}{*}{$\begin{array}{l}\text { Significant } \\
\text { Negative } \\
\text { Slope } \\
\text { (1-sided } 5 \% \\
\text { significance) }\end{array}$} & \multirow[t]{2}{*}{$\begin{array}{c}\text { Relative } \\
\text { Meas. Error }\end{array}$} & \multirow{2}{*}{$\begin{array}{l}\text { Change in } \\
\text { conc. at } 28 \\
\text { days } \\
\text { (ppb) }\end{array}$} & \multirow{2}{*}{$\begin{array}{l}\% \text { Change in } \\
\text { conc. at } 28 \\
\text { days }\end{array}$} \\
\hline & & $\begin{array}{c}\text { Intercept } \\
\text { (ppb) }\end{array}$ & $\begin{array}{c}\text { Slope } \\
\text { (ppb/day) }\end{array}$ & & & & \\
\hline \multicolumn{8}{|l|}{ SAMPIESETWI } \\
\hline Acetone & 16 & 21.2 & 0.0124 & $\mathrm{NO}$ & $10 \%$ & - & - \\
\hline Benzene & 28 & 16.1 & 0.0033 & $\mathrm{NO}$ & $5 \%$ & - & - \\
\hline Carbon disulfide & 28 & 15.2 & -0.0501 & YES & $6 \%$ & -1.4 & $-9 \%$ \\
\hline Carbon tetrachloride & 28 & 16.6 & -0.0168 & YES & $6 \%$ & -0.5 & $-3 \%$ \\
\hline Chlorobenzene & 28 & 16.8 & -0.0134 & YES & $5 \%$ & -0.4 & $-2 \%$ \\
\hline Chloroform & 28 & 18.0 & 0.0056 & NO & $6 \%$ & - & - \\
\hline Dichloroethene, trans-1,2- & 28 & 15.6 & -0.0211 & YES & $5 \%$ & -0.6 & $-4 \%$ \\
\hline Methylene chloride & 28 & 17.5 & -0.0007 & NO & $5 \%$ & - & - \\
\hline Pentanone,4-methyl-2- & 24 & 18.3 & 0.0082 & NO & $7 \%$ & - & - \\
\hline Styrene & 28 & 17.7 & 0.0099 & NO & $12 \%$ & - & - \\
\hline Tetrachloroethene & 28 & 18.1 & -0.0654 & YES & $9 \%$ & -1.8 & $-10 \%$ \\
\hline Toluene & 28 & 15.2 & -0.0005 & NO & $6 \%$ & - & - \\
\hline Trichloroethane, $1,1,1$ - & 28 & 15.6 & 0.0034 & NO & $8 \%$ & - & - \\
\hline Trichloroethene & 28 & 16.9 & -0.0103 & NO & $5 \%$ & - & - \\
\hline Vinyl acetate & 20 & 23.5 & -0.3486 & YES & $21 \%$ & -9.8 & $-42 \%$ \\
\hline Vinyl chloride & 24 & $\mathbb{1 0 . 9}$ & 0.0915 & NO & $43 \%$ & - & - \\
\hline Xylene, m,p- & 28 & 37.4 & -0.0752 & YES & $10 \%$ & -2.1 & $-6 \%$ \\
\hline Xylene, $0-$ & 28 & 18.7 & -0.0268 & NO & $11 \%$ & - & - \\
\hline \multicolumn{8}{|l|}{ SAMPLESET W2 } \\
\hline Acetone & 16 & 194.5 & -0.2472 & NO & $9 \%$ & - & - \\
\hline Benzene & 27 & 177.7 & -0.2523 & NO & $10 \%$ & - & - \\
\hline Carbon disulfide & 27 & 200.8 & -1.2258 & YES & $8 \%$ & -34.3 & $-17 \%$ \\
\hline Carbon tetrachloride & 27 & 199.0 & -0.6786 & YES & $13 \%$ & -19 & $-10 \%$ \\
\hline Chlorobenzene & 27 & 182.0 & -0.3897 & YES & $9 \%$ & -10.9 & $-6 \%$ \\
\hline Chloroform & 27 & 194.0 & -0.3069 & YES & $10 \%$ & -8.6 & $-4 \%$ \\
\hline Dichloroethene, trans-1,2- & 27 & 176.5 & -0.5698 & YES & $9 \%$ & -16 & $-9 \%$ \\
\hline Methylene chloride & 27 & 179.3 & -0.1591 & NO & $9 \%$ & - & - \\
\hline Pentanone,4-methyl-2- & 23 & 210.6 & -0.0675 & NO & $5 \%$ & - & - \\
\hline Styrene & 27 & 174.7 & -0.6391 & YES & $5 \%$ & -17.9 & $-10 \%$ \\
\hline Tetrachloroethene & 27 & 166.5 & -0.9265 & YES & $8 \%$ & -25.9 & $-16 \%$ \\
\hline Toluene & 27 & 178.6 & -0.1996 & NO & $16 \%$ & - & - \\
\hline Trichloroethane, 1,1,1- & 27 & 182.3 & -0.5152 & YES & $12 \%$ & -14.4 & $-8 \%$ \\
\hline Trichloroethen & 27 & 193.7 & -0.5018 & YES & $11 \%$ & -14.1 & $-7 \%$ \\
\hline Vinyl acetate & 19 & 235.4 & -3.5267 & YES & $19 \%$ & -98.7 & $-42 \%$ \\
\hline Vinyl chloride & 23 & 144.0 & -0.0040 & NO & $33 \%$ & - & - \\
\hline Xylene, m,p- & 27 & 343.6 & -1.1289 & YES & $7 \%$ & -31.6 & $-9 \%$ \\
\hline Xylene, $0-$ & 27 & 172.2 & -0.4257 & YES & $6 \%$ & -11.9 & $.7 \%$ \\
\hline
\end{tabular}


Table 2. Maximum holding times for compounds in sample sets W1 and W2. Also includes relative change in concentration after 28 days of storage.

\begin{tabular}{|c|c|c|c|c|}
\hline \multirow[b]{2}{*}{ Compound } & \multicolumn{2}{|c|}{$\frac{\text { Sample Set W } 120 \mathrm{ppb}}{\text { spike) }}$} & \multicolumn{2}{|c|}{$\begin{array}{c}\text { Sample Set W2 } 200 \mathrm{ppb} \\
\text { spike) }\end{array}$} \\
\hline & $\begin{array}{c}\text { Max. } \\
\text { holding time } \\
\text { (days) }\end{array}$ & $\begin{array}{c}\% \text { Change in } \\
\text { conc. at } 28 \\
\text { days }\end{array}$ & $\begin{array}{l}\text { Max. holding } \\
\text { time (days) }\end{array}$ & $\begin{array}{c}\text { \%Change in } \\
\text { conc. at } 28 \\
\text { days }\end{array}$ \\
\hline \multicolumn{5}{|c|}{ Group $\mathrm{L}$ Max holdine time greater than or equal to 28 davs } \\
\hline Acetone & 71 & - & 71 & - \\
\hline Acrylonitrile & 71 & - & 71 & - \\
\hline Benzene & 71 & - & 71 & - \\
\hline Bromomethane & 71 & - & 71 & - \\
\hline 2-Butanone & 71 & - & 71 & - \\
\hline roethane, 1,1 - & 71 & - & 71 & - \\
\hline Dichloroethane,1,2- & 71 & - & 71 & - \\
\hline Dichloroethene, 1,1- & 71 & - & 71 & - \\
\hline ropropane, 1,2 & 71 & - & 71 & - \\
\hline methane & 71 & - & 71 & - \\
\hline one, 4-methyl-2- & 71 & - & 71 & - \\
\hline Joroethane, $1,1,2,2$ - & 71 & - & 71 & - \\
\hline Tolt & 71 & _ & 71 & _- \\
\hline roethane, $1,1,2$ - & 71 & - & 71 & - \\
\hline hloride & 71 & - & 71 & - \\
\hline hloromethane & 71 & - & 45 & - \\
\hline trachloride & 43 & - & 28 & - \\
\hline nzene & 40 & - & 28 & - \\
\hline Chlo & 71 & - & 34 & - \\
\hline Chlor & 71 & - & 44 & - \\
\hline Trichloroethane,1,1,1- & 71 & - & 30 & - \\
\hline roethene & 71 & - & 31 & - \\
\hline Methyl iodide & 71 & - & 37 & - \\
\hline \multicolumn{5}{|c|}{ Group 2: Max holding time less 28 davs and \%change at 28 davs $<10 \%$} \\
\hline Chloromethane & 23 & $-5 \%$ & 22 & $-10 \%$ \\
\hline ane & 25 & $-4 \%$ & 20 & $-9 \%$ \\
\hline loroethene & 30 & - & 23 & $-10 \%$ \\
\hline Dichloroethene & 24 & $-4 \%$ & 20 & $-9 \%$ \\
\hline Ethy lbenzene & 40 & - & 25 & $-8 \%$ \\
\hline chloromethane & 71 & - & 14 & $-6 \%$ \\
\hline ene & 36 & - & 14 & $-9 \%$ \\
\hline o-Xylene & 71 & - & 17 & $-7 \%$ \\
\hline Styrene & 71 & - & 9 & $-10 \%$ \\
\hline Bror & 71 & - & 15 & $-6 \%$ \\
\hline 2-Hexanone & 71 & - & 7 & $.9 \%$ \\
\hline 1,2,3-Trichloropropane & 71 & - & 12 & $-6 \%$ \\
\hline \multicolumn{5}{|c|}{ Group 3: Max holding time less than 28 daus and \%change at 28 davs $>10 \%$} \\
\hline Trichlorofluoromethane & 16 & $-8 \%$ & 14 & $-15 \%$ \\
\hline Acrolein & - & - & 4 & $-25 \%$ \\
\hline Carbon disulfide & 13 & $-9 \%$ & 9 & $-17 \%$ \\
\hline Vinyl a & 10 & $-42 \%$ & 9 & $-42 \%$ \\
\hline cis-1,3-Dichloropropene & 12 & $-11 \%$ & 13 & $-14 \%$ \\
\hline 1,3-Dichloropropene & 17 & $.9 \%$ & 16 & $-12 \%$ \\
\hline Tetr & 17 & $-10 \%$ & 9 & $-16 \%$ \\
\hline trans-1,4-Dichloro-2-butene & 16 & $-20 \%$ & 3 & $-26 \%$ \\
\hline
\end{tabular}


Calculated $M H T$ s were very short for some analytes with very low measurement variability, even though concentration changes on the 28th day were relatively small (e.g., styrene in set $\mathrm{W} 2: \% R M E=5.0 \%, M H T=9.4$ days, \%change on the 28 th day relative to initial concentration $=-10 \%$ ). In such cases, factors other than calculated $M H T$ s should be considered when assessing the effects of holding times on measurement validity. Statistical definitions of significant concentration change, such as the practical report time approach [Bayne et al., 1994], must be complemented with "practical" definitions of "acceptable" concentration change. Ideally, specifications for "acceptable" concentration changes should be tied into the eventual use of the analytical data. For example, "acceptable" concentration changes for analytical data used in quantitative risk assessments can be determined by the sensitivity of the risk assessment results to variations in the input analytical data. Since, the selection of a generic "acceptable" concentration change was beyond the scope of this study, 10\% was chosen as a reasonable value to assess the holding time effects on analyses.

Based on calculated MHTs and an "acceptable" concentration change of $10 \%$ for lowvariability analytes, the stability study showed that the measurement of 36 out of 44 purgeable VOCs in properly preserved water samples will not be affected by sample storage for 28 days. Larger changes in concentration $(>10 \%)$ and low MHTs were observed for a few analytes (see Group 3 in Table 2). However, additional analytical problems for some of the latter compounds exist (e.g., inconsistent purging) which can confound the analytical process and which can not be addressed by restricting maximum holding times alone.

\section{Summary}

This study demonstrates that a 28-day holding time for properly preserved water samples would not jeopardize the measurement of VOCs. This holding time extension would benefit the regulated community, particularly government agencies with large-scale compliance sampling programs such as the Department of Defense and Department of Energy. Stringent holding times result in logistical difficulties further complicated by additional requirements for sample screening (e.g., for radioactivity). The suggested modification of holding times can also improve the sample through-put of commercial laboratories through simplified sample management. Application to data review of the database generated by this study would also improve the analytical data validation process by providing an alternative to the currently "one-size-fits-all" accept or reject approach that is very costly but not technically defensible.

This study also demonstrated a methodology for conducting a stability study and practical reporting time analysis of the stability data. The latter approach would be useful for establishing site-specific maximum holding times which, depending on the compounds of interest, can be longer than 28 days. 


\section{Acknowledoments}

The authors would like to acknowledge the following who contributed towards the successful completion of this work: Barry Lesnik, Ray Bath, and Alan Hewitt for reviewing our experimental plan; EPA Region VI for conducting the data validation; EPA Region IV for participating in the holding time study; and Analytical Resources Inc. for providing high-quality and timely VOC analyses. This project was funded by the Department of Energy's Analytical Programs Office.

\section{References}

[1] Bayne, C. K.; Schmoyer, D. D.; Jenkins, R. A. 1994. Practical Reporting Times for Environmental Samples. Environ. Sci. Technol. 28, 1430-1436.

[2] Bottrell, D. W.; Fisk, J. F.; Dempsey, C. 1989. Pre-analytical Holding Time Study Volatiles in Water. Proceedings Fifth Annual Symposium on Solid Waste Testing and Quality Assurance. U.S. Environmental Protection Agency. II:24.

[3] Bottrell, D. W. Suggested Modification of Pre-analytical Holding Times - Volatile Organics in Water Samples. Proceedings Eleventh Annual Waste Testing and Quality Assurance Symposium. American Chemical Society and U.S. Environmental Protection Agency. 507-516.

[4] Federal Register. 1979. 40CFR Part 136. Proposed Rules, Vol. 44, No. 233: 69534. Dec. 3.

[5] Federal Register. 1984. 40CFR Part 136. Rules and Regulations. Vol. 49, No. 209: 145. Oct. 26.

[6] Maskarinec, M. P.; Bayne, C. K.; Johnson, L. H.; Holladay, S. K.; Jenkins, R. A. 1989. Stability of Volatile Organics in Environmental Water Samples: Storage and Preservation. ORNL/TM-11300. Oak Ridge National Laboratory, Oak Ridge, TN.

[7] U.S. Environmental Protection Agency. Test Methods for Evaluating Solid Waste, 3rd ed.; SW-846; U.S. EPA: Washington, DC, 1986. (Method 8260-A, Revision 1, 1994).

[8] U. S. Environmental Protection Agency. 1994. Contract Laboratory Program Functional Guidelines for Organic Data Review, EPA-540/R-94/012. U.S. Environmental Protection Agency, Office of Solid Waste and Emergency Response. Washington, D.C. [9] West, O. R.; Bayne, C. K.; Holden, W. L.; Siegrist, R. L.; Scarborough, S. S.; Bottrell, D. W. 1996. A Confirmatory Holding Time Study for Purgeable VOCs in Water Samples. ORNL/TM-13240. Oak Ridge National Laboratory, Oak Ridge, TN.

[10] West, O. R.; Bayne, C. K.; Holden, W. L.; Siegrist, R. L.; Bottrell, D. W. 1996. The Stability of Volatile Organic Compounds in Water Samples. (manuscript in preparation). 